\title{
Quatro décadas de Educação Especial no Estado de São Paulo
}

\author{
Four decades of Special Education in Sao Paulo State \\ Cuatro décadas de Educación Especial en Estado de San Paulo
}

\author{
Sadao Omote \\ Professor Adjunto na Universidade Estadual Paulista, Marília, São Paulo, Brasil. \\ somote@uol.com.br \\ ORCID - http://orcid.org/0000-0003-2455-4529
}

Recebido em 12 de agosto de 2020

Aprovado em 12 de agosto de 2020

Publicado em 17 de novembro de 2020

\section{RESUMO}

A formação de profissionais de Educação Especial no Brasil é relativamente recente. Inicialmente, os professores especializados no ensino de estudantes com deficiência eram formados em cursos de especialização após o curso colegial. Neste artigo, são analisados os avanços ocorridos, nas últimas quatro décadas, em relação à formação de professores e pesquisadores em Educação Especial, no Estado de São Paulo, bem como mudanças nos aspectos conceituais e metodológicos de estudo das deficiências e do atendimento a pessoas com deficiência. Na década de 1970, dois movimentos universitários deram nova dimensão à formação de recursos humanos em Educação Especial: o início das Habilitações em Educação Especial no curso de Pedagogia da Universidade Estadual Paulista "Júlio de Mesquita Filho" (HEE/UNESP), em 1977, e o início do Programa de Mestrado em Educação Especial da Universidade Federal de São Carlos (PMEE/UFSCar), em 1978. A HEE/UNESP passou a formar professores de Educação Especial e o PMEE/UFSCar, a formar pesquisadores em Educação Especial. Esses fatos foram fundamentais para o enorme crescimento que a área teve nestas quatro décadas. São destacadas as mudanças que estão ocorrendo nas questões conceituais a respeito das deficiências e no delineamento de pesquisa.

Palavras-chave: Educação Especial; Formação do professor; Formação do pesquisador.

\section{ABSTRACT}

Special Education professionals' training in Brazil is relatively recent. Initially, teachers for students with disabilities were trained in specialization courses at the end of Senior High School. This article analyzes the advances in the teachers' and researchers' training in Special Education in São Paulo State as well as changes in the conceptual and methodological aspects of the study of disabilities and assistance for people with disabilities in the last four decades. In the 1970s, two college events gave a new dimension to the formation of human resources in Special Education: the beginning of the Qualification in Special Education in Pedagogy course at the São Paulo State University (HEE/UNESP), in 1977, and the beginning of the Master Program in Special Education at the Federal University of São Carlos (PMEE/UFSCar), in 1978. The HEE/UNESP began to train Special Education teachers and the PMEE/UFSCar, to train researchers in Special Education. These facts were fundamental to the enormous growth that the area of Special 
http://dx.doi.org/10.5902/1984686X53133

Education had had in these four decades. The changes that are occurring in the conceptual questions regarding deficiencies and in the research design are highlighted.

Keywords: Special Education; Teacher training; Researcher training.

\section{RESUMEN}

La formación de profesionales de Educación Especial en Brasil es relativamente reciente. Inicialmente, los maestros especializados em educación escolar com discapacidades fueron capacitados en cursos de especialización después de la Educación Secundaria. En este artículo se analizan los avances que se han producido em las últimas cuatro décadas en relación com la formación de profesores y investigadores em Educación Especial en Estado de San Paulo así como câmbios em los aspectos conceptuales y metodológicos del estudio de las discapacidades y la atención a las personas com discapacidad. Em la década de 1970, dos movimientos universitários dieron una nueva dimensión a la formación de los recursos humanos em la Educación Especial: el inicio de las Habilitación em Educación Especial em el curso de Pedagogía de la Universidad Estatal de San Paulo "Júlio de Mesquita Filho (HEE/UNESP), em 1977, y el inicio del Máster em Educación Especial de la Universidad Federal de San Carlos (PMEE/UFSCar), en 1978. La HEE/UNESP comenzó a capacitar a maestros em Educación Especial y el PMEE/UFSCar, a capacitar a investigadores de Educación Especial. Estos hechos fueron fundamentales para el enorme crecimiento que ha tenido la área en estas cuatro décadas. Se destacan los cambios que se están produciendo em las cuestiones conceptuales com respecto a las deficiencias y en el diseño de la investigación.

Palabras clave: Educación Especial; Formación de maestros; Formación de investigadores.

\section{Introdução}

Quatro décadas representam um período muito curto, que pode até sugerir um quadro relativamente estacionário sem a ocorrência de grandes transformações. Entretanto, quem tem 50 anos ou mais certamente irá se lembrar de muitas mudanças ocorridas nestes quarenta anos, podendo até arrolar fatos marcantes de cada década. Quem tem 70 anos ou mais certamente se lembrará de mudanças espetaculares ocorridas nas décadas de 1960 e 1970, especialmente em termos sociais, com a construção de novos modos de pensar e de agir. Foi o tempo de muitas contestações, à beira de rebeldia aos olhos dos mais conservadores, rompendo com muitas tradições até então consolidadas. As quatro décadas seguintes herdaram o compromisso de concretizar essa necessidade de transformação que fora escancarada.

É uma maneira estranha de iniciar um texto que se pretende acadêmico. Pertenço à geração mais velha ainda em atividade. Costumo dizer que me sinto privilegiado por ter vivido as inquietações, as incertezas e a energia da adolescência e da juventude na década de 1960. E é nessa perspectiva que resolvi trazer neste texto, talvez com um tom de 
nostalgia e de desabafo, a percepção de quem construiu a sua maturidade acadêmica nas últimas quatro décadas ${ }^{1}$. Talvez o depoimento de quem viveu esse período na primeira pessoa possa ser heuristicamente mais interessante que uma breve tentativa de historiografia por meio de análise documental, ensejando reflexões que possam quiçá contribuir para incorporar alguns ingredientes adicionais à discussão sobre a Educação Especial e Educação Inclusiva.

A assistência a pessoas com deficiência ${ }^{2}$ efetivamente começa a ser sistematizada a partir de meados do século XIX no Brasil. Dois fatos importantes desse período são constantemente lembrados: a criação do Imperial Instituto dos Meninos Cegos e a do Instituto dos Surdos Mudos, posteriormente alteradas as designações para Instituto Benjamin Constant e Instituto Nacional de Educação dos Surdos respectivamente. Em meados do século $\mathrm{XX}$, foram criadas várias instituições de atendimento a pessoas com deficiência. Podem-se destacar particularmente o Instituto Pestalozzi, Instituto Santa Teresinha, Lar Escola São Francisco, Sociedade Pestalozzi, Associação de Assistência à Criança Deficiente e Associação de Pais e Amigos dos Excepcionais. Um pouco mais recentemente, em 1973, a criação do Centro Nacional de Educação Especial, no Ministério da Educação e Cultura, representou, ainda que um tanto timidamente, um importante marco para a participação efetiva do poder público na questão da educação de pessoas com deficiência. Finalmente, marcos internacionais significativos podem ser identificados na Declaração de Jomtiem (1990) e principalmente na de Salamanca (1994) ${ }^{3}$.

O período a que se refere a presente análise se inicia na década de 1970, quando alguns fatos significativos inauguraram um novo período de formação de recursos humanos - professores e pesquisadores - que afetou profundamente $o$ atendimento a pessoas com deficiência e a construção de conhecimentos na área de Educação Especial. Esta análise tem como ponto de partida dois movimentos universitários ocorridos no Estado de São Paulo. Referem-se à criação da Habilitação em Educação Especial no curso de Pedagogia da Universidade Estadual Paulista, campus de Marília, e do Programa de Mestrado em Educação Especial da Universidade Federal de São Carlos ${ }^{4}$.

No fim da década de 1960 para o início da de 1970, houve várias tentativas de normatização da educação de crianças e jovens com deficiência, incluindo a questão da formação do professor especializado no ensino de deficientes. O Estado de São Paulo fez opção pela formação do professor especializado no ensino de deficientes em nível de curso superior, na modalidade de habilitação do curso de Pedagogia, conforme Deliberação no 
http://dx.doi.org/10.5902/1984686X53133

15/71 do Conselho Estadual de Educação, em obediência ao Parecer № 252/69 do Conselho Federal de Educação.(UNESP, 1977).

Coincidindo com o início do período de expansão da rede privada de ensino universitário, alguns cursos de Pedagogia criaram essa habilitação, principalmente na área da deficiência mental ${ }^{5}$. A experiência desenvolvida nas Faculdades particulares se mostrou insatisfatória, devido a dificuldades decorrentes da própria condição de funcionamento de instituições universitárias privadas que ainda estavam buscando a sua consolidação. Especificamente em relação aos cursos de formação de professores de deficientes mentais, Enumo (1985) apontou algumas dessas dificuldades: (a) a contratação de docentes por hora-aula, o que limitava o contato deles com a escola e os alunos; (b) a ausência de projeto pedagógico na maioria dos cursos; (c) pequena carga horária de estágios supervisionados, cuja prática era prejudicada, pois a maioria dos cursos funcionava no período noturno, ao passo que as classes especiais nas quais os alunos deveriam fazer o estágio funcionavam no período diurno; e, (d) bibliotecas limitadas com irrisória bibliografia da área disponível para professores e alunos ${ }^{6}$.

Em vista desse precário quadro de formação de professores especializados no ensino de deficientes no Estado de São Paulo, um grupo de trabalho elaborou um projeto de formação de professores no ensino de deficientes, em 1975, propondo a implantação da Habilitação em Educação Especial já em 1976 nos cursos de Pedagogia da Faculdade de Filosofia, Ciências e Letras de Franca, São José do Rio Preto e Marília ${ }^{7}$. Ocorre que, em 1976, foi criada a Universidade Estadual Paulista "Júlio de Mesquita Filho" (UNESP), com a reunião dos Institutos Isolados de ensino superior. Em obediência a um princípio norteador da criação da UNESP, os cursos de Pedagogia de Franca e São José do Rio Preto foram extintos ${ }^{8}$.

Em vista da nova realidade universitária, foi instituída a Comissão de Educação Especial na recém-criada UNESP para adequar o projeto que fora apresentado por aquele grupo de trabalho. Essa Comissão concluiu pela criação da Habilitação em Educação Especial no curso de Pedagogia da UNESP de Marília, que não fora extinto. Assim, em 1977, teve início a Habilitação em Educação Especial (HEE/UNESP), que compreendia quatro áreas distintas, uma para cada deficiência. As áreas de deficiência mental e deficiência visual tiveram início em 1977; as áreas de deficiência da audiocomunicação ${ }^{9} \mathrm{e}$ deficiência física foram implantadas respectivamente em 1980 e 1986. 
http://dx.doi.org/10.5902/1984686X53133

Nessa mesma oportunidade, fatos relevantes ocorridos na Universidade Federal de São Carlos (UFSCar) contribuíram significativamente para a trajetória percorrida pela HEE/UNESP. Arrisco-me a supor que, em alguma extensão, a recíproca é verdadeira. A UFSCar ofereceu, em 1977, um curso de especialização para professores do ensino especial, que revelou haver uma demanda reprimida para a capacitação de docentes nessa área, em vista da institucionalização pelo Governo do Estado de uma sistemática de formação de recursos humanos em Educação Especial. A UFSCar deu início ao Programa de Mestrado em Educação Especial (PMEE/UFSCar) em 1978, visando a formar recursos humanos que atendessem à nova demanda de formação de docentes, pesquisadores e técnicos em alto nível.

Quando a UNESP iniciou a Habilitação em Educação Especial, em 1977, havia, no campus de Marília, apenas uma docente com formação na área, feita em curso de especialização que era oferecido aos egressos de curso colegial (antigo 2 Grau e atual Ensino Médio). Essa professora, que estava cursando o Mestrado em São Paulo, ficou encarregada de compor o corpo docente e cuidar da implantação da Habilitação em Educação Especial. No final da década de 1970 e no início da de 1980, ainda havia muita carência de professores universitários com título acadêmico de mestre ou doutor, especialmente em cidade de médio ou pequeno porte e distante de grandes centros urbanos. Assim, os primeiros docentes contratados para as áreas de deficiência mental, deficiência visual e deficiência da áudio-comunicação foram recomendados em função da sua experiência profissional na área e não em função da sua experiência de pesquisa ou formação acadêmica na área ${ }^{10}$.

No decorrer dos 34 anos de funcionamento da HEE/UNESP, vários docentes deixaram a sua contribuição, alguns por um breve tempo e outros até a sua aposentadoria. A formação acadêmica desse corpo docente foi fortemente influenciada pelo PMEE/UFSCar. Essa parceria informal e casual entre a HEE/UNESP e PMEE/UFSCar foi profícua e contribuiu para a construção da configuração atual da Educação Especial e Educação Inclusiva. Favoreceu também a emergência de uma área a requerer a formação de profissionais e pesquisadores de alto nível, além de constituir um campo de investigação muito fértil ${ }^{11}$.

Dentre as várias mudanças ocorridas nessa caminhada de quatro décadas, vou me deter em duas delas para as quais essa parceria pode ter contribuído de modo significativo, 
http://dx.doi.org/10.5902/1984686X53133

o que, após uma longa introdução, é o escopo central deste texto. Referem-se a mudanças na concepção de deficiência e no delineamento de pesquisa.

\section{Mudanças na Concepção de Deficiência}

Desde que, alguns séculos atrás, a assistência a pessoas deficientes passou a ser oferecida de modo sistemático e propositado, com algum suporte científico, a concepção que norteou as atividades profissionais por longas décadas pode ser caracterizada genericamente como médico-pedagógica. Esta concepção está fundada na ideia central de que a deficiência é o efeito deletério de alguma patologia da qual uma pessoa é portadora. Algumas definições clássicas de deficiência mental, em meados do século passado, enfatizam o caráter constitucional dela. Conforme Telford e Sawrey (1976), Doll destacou, em 1941, que a subnormalidade mental resulta da paralisação de desenvolvimento, cuja origem é constitucional. Mais ainda, aponta que ela é essencialmente incurável. (havia aqui um período que foi excluído) A American Association on Mental Deficiency (AAMD) ${ }^{12}$, uma das mais antigas associações científicas da área, vem atualizando periodicamente a sua definição, acompanhando as mudanças ocorridas continuamente na concepção e prática em relação a pessoas com deficiência mental. Nas sucessivas atualizações, introduziu o conceito de comportamento adaptativo, apontando a sua deterioração como uma característica da deficiência mental (HEBER,1961). Se a referência à deterioração no comportamento adaptativo ainda poderia sugerir a incurabilidade da deficiência mental, (havia aqui um trecho que foi excluído) a revisão da AAMD de 1973 substitui aquela expressão por déficit no comportamento adaptativo (GROSSMAN, 1973), que talvez sugira mais claramente a possibilidade de intervenção para ampliar o repertório comportamental.

A profissionalização crescente dos serviços de atendimento a deficientes, abandonando abordagem essencialmente assistencialista que caracterizava muitos dos serviços destinados a pessoas com deficiência, contribuiu tanto para a compreensão e aceitação da possibilidade de modificação do quadro comportamental representado pela deficiência quanto para buscar determinantes sociais e interacionais, além das causas constitucionais. Na tentativa de construir alguma sistematização, delineei dois conjuntos solidariamente interdependentes de determinantes do quadro comportamental de deficiências, aos quais me referi por condições médicas incapacitadoras e condições sociais incapacitadoras (OMOTE, 1979). Embora o título do artigo especifique a deficiência mental, toda a discussão desenvolvida se refere a deficiências em geral. Na realidade, era 
http://dx.doi.org/10.5902/1984686X53133

uma breve formalização de um pensamento que hoje não gera dúvida nenhuma, o de que o quadro comportamental apresentado por uma pessoa com deficiência é resultado do efeito conjunto e interativo de determinantes constitucionais e sociais.

Uma outra mudança na concepção de deficiência, que considero de grande relevância, vem modificando paulatinamente a natureza dos serviços oferecidos e dos objetos de pesquisa. O projeto da HEE/UNESP elaborado pela Comissão de Educação Especial havia concebido quatro áreas distintas, uma para cada deficiência, e apresentava apenas uma disciplina comum aos currículos das quatro áreas. Tratava-se de Fundamentos da Educação Especial, cujo conteúdo programático versava sobre fundamentos legais e diferentes modalidades de atendimento em Educação Especial. Na segunda turma, iniciada em 1978, foram introduzidas duas disciplinas comuns às duas áreas de deficiência em implantação naquele momento. Eram Alterações Sensoriais e Motoras de Crianças Deficientes e Divergências Sociais. O propósito das disciplinas era o de tratar de questões comuns às quatro deficiências ${ }^{13}$. No decorrer dos 34 anos de funcionamento da HEE/UNESP, a carga horária comum às quatro áreas de deficiência foi aumentando progressivamente. Quando foi extinta em 2010, cerca de 1/3 da carga horária se referia a disciplinas comuns a todas as áreas.

Essa mudança parece ser uma decorrência natural do reconhecimento das abordagens sociais, que permitiram compreender fenômenos que afetavam as diferentes categorias de pessoas deficientes, na medida em que as pessoas com deficiência eram percebidas e tratadas primariamente como membros de grupos minoritários e secundariamente como membros de algum grupo minoritário específico, identificado por um rótulo que designava alguma deficiência. As patologias específicas implicam diferentes consequências sobre o seu portador, razão pela qual considerar devidamente as especificidades é fundamental. Por outro lado, nem todas as diferenças e dificuldades apresentadas por pessoas com deficiência são decorrências dessas patologias, mas também do lugar social reservado a elas e do papel social que lhes é prescrito, como membros de grupos minoritários. Essa compreensão levou os estudiosos a considerar não apenas as especificidades, mas também o que há de comum entre pessoas com diferentes deficiências.

Essa tendência pode ser verificada claramente tanto nos serviços de atendimento quanto nas pesquisas. As instituições tradicionais destinadas ao atendimento de pessoas com deficiência continuam, de um modo geral, dedicadas a deficiências específicas. Mas, 
http://dx.doi.org/10.5902/1984686X53133

a educação escolar de estudantes com deficiência mudou radicalmente, principalmente em função do modelo de Educação Inclusiva em implantação no sistema educacional brasileiro. Os profissionais de Educação Especial não mais são formados para áreas especificas de deficiência. O estudante com qualquer tipo de necessidades educacionais especiais pode ser inserido em uma classe de ensino comum ${ }^{14}$.

A trajetória percorrida pela terminologia da área sugere mais claramente essa tendência. Até a década de 1970, inclusive, os nomes eram específicos para designar cada tipo de excepcionalidade ${ }^{15}$. As mudanças na terminologia ocorridas antes da década de 1980 se caracterizavam fundamentalmente pela substituição de um nome por outro, por considerar que aquele era inadequado, por diferentes razões, para designar uma determinada condição, sempre com referência a categorias ou subcategorias específicas ${ }^{16}$.

Na década de 1980, quando o modelo integracionista de atendimento especializado a deficientes, sobretudo na rede pública de ensino, passou a ser mais intensamente criticado, alguns ensaios de utilização de designações genéricas foram observados. Incluíam termos como portador de deficiência e pessoa com deficiência. A Declaração de Salamanca consagrou um nome genérico sem estabelecer distinções que estavam sendo feitas até então. O termo necessidades educacionais especiais (NEE) foi prontamente incorporado no discurso de Educação Especial brasileira. Alguma possibilidade de retorno à especificidade parece ter sido vislumbrada, quando, por um breve período de tempo, algumas pessoas, após usar o termo NEE, passaram a especificar a que tipo de necessidade estavam se referindo. Talvez isso tenha contribuído para que fosse cunhado o termo atual, aparentemente bem acolhido: o público-alvo da Educação Especial. Por ora parece não haver necessidade de desmembrar esse público em algumas categorias específicas. Mas, menção específica a deficiências, transtorno global do desenvolvimento e superdotação/altas habilidades tem ocorrido em contextos que não tratam amplamente dos serviços destinados a esse público.

$\mathrm{Na}$ área da pesquisa, os estudos se referiam predominantemente a uma categoria específica de deficiência, sendo a mental a mais frequentemente investigada. Esse quadro também parece estar sofrendo mudanças. No levantamento feito entre os trabalhos apresentados em três edições de quatro grandes eventos científicos no Brasil ${ }^{17}$, no período de 2008 a 2013, 26\% deles se referiam a duas ou mais categorias de necessidades educacionais especiais. Outros trabalhos, correspondendo a $74 \%$ se referiam a uma categoria específica de necessidades educacionais especiais, sendo a deficiência mental, 
http://dx.doi.org/10.5902/1984686X53133

correspondendo a 13\%, a mais frequente entre os trabalhos feitos com uma única categoria de necessidades educacionais especiais (GLAT; OMOTE; PLETSCH, 2014). Estudos semelhantes feitos com trabalhos apresentados em dois grandes eventos e com artigos publicados em um periódico, na década de 1990, haviam indicado a predominância da categoria de deficiência mental, representando mais de $50 \%$ dos trabalhos nos quais uma única deficiência foi especificada (OMOTE, 2003).

Essa tendência pode ser observada também na transição do PMEE para o Programa de Pós-Graduação em Educação Especial (PPGEEs) na UFSCar. O PMEE tinha como área de concentração a "Deficiência Mental". Já na reformulação ocorrida em 1990, quando a nova designação do Programa foi instituída, a área de concentração passou a ser "Educação do Indivíduo Especial". Não disponho de dados, mas suponho que essa mudança pode ter contribuído para favorecer as pesquisas envolvendo participantes com as mais variadas necessidades educacionais especiais.

O foco na especificidade de cada deficiência, como no passado, pode levar o estudioso a atribuir, a uma condição específica, problemas decorrentes de determinantes sociais relativamente comuns a grupos minoritários em geral. Se um surdo encontra dificuldade para se inserir no mercado de trabalho, não é exata ou necessariamente em decorrência da surdez, mas provavelmente podem ser identificados determinantes que não têm relação direta com a surdez, tais como a dificuldade de relacionamento devido à comunicação limitada, preconceito e estigma, precária formação ocupacional, etc. Há, afinal, uma enorme gama de atividades ocupacionais, para cujo exercício competente, a comunicação oral não se constitui em um pré-requisito.

As pesquisas com duas ou mais categorias de excepcionalidade podem permitir a identificação de problemas específicos e os comuns, tanto constitucionais quanto sociais, o que pode fornecer fundamentos confiáveis na organização de serviços. Dependendo da natureza da dificuldade, um atendimento específico e diferenciado para uma categoria pode ser recomendável até em separado. O atendimento em separado, temporal e espacialmente, não significa necessariamente segregação, a qual parece constituir-se ainda em uma espécie de fantasma a assombrar o atendimento a pessoas com deficiência. No passado recente, houve críticas em relação à segregação decorrente de colocação em serviços diferenciados como classes especiais. Daí, foram criticados como segregativos. Conforme já apontei em algumas ocasiões (OMOTE, 1995, 1999, 2000, 2012), nenhum recurso é inerentemente segregativo. É o seu uso que pode promover a segregação, ou a 
http://dx.doi.org/10.5902/1984686X53133

integração/inclusão. Esse mau uso foi amplamente evidenciado em várias pesquisas, envolvendo suspeitas iniciais enviesadas (SCHNEIDER, 1974), identificação e encaminhamentos equivocados (ALMEIDA, 1984; DENARI, 1984; PASCHOALICK, 1981; RODRIGUES, 1982) e manutenção prolongada e equivocada em classes especiais (PIROVANO, 1996)

O nome Educação Especial, que ameaçou ser esquecido e substituído integralmente por Educação Inclusiva, no clima de grande entusiasmo pelas propostas da Declaração de Salamanca, cedo recuperou o seu lugar. No passado, Educação Especial sugeria de imediato algo separado da Educação de um modo geral, destinada a uma clientela específica e praticada por um pequeno contingente de educadores especiais, talvez vistos como um tanto excêntricos. Hoje a Educação Especial aparece juntamente com a Educação Inclusiva. Parece haver relativo consenso de que, para a construção da Educação Inclusiva, os recursos da Educação Especial são necessários. Portanto, são indissociáveis. Aliás, mais do que isso, na verdade, busca-se construir Educação de qualidade para todas as pessoas com o uso de todos os recursos disponíveis. Não deveria haver embaraço nenhum em estender a qualquer pessoa o uso de recursos desenvolvidos e tradicionalmente utilizados no atendimento a pessoas com uma deficiência específica. Naturalmente, o uso de recurso especial pode levar os usuários a eventualmente serem estigmatizados, pelo significado que é atribuído a ele. Evidencia-se, assim, claramente a necessidade de uma ampla abordagem capaz de equacionar as variáveis sociais, cujo manejo precisa fazer parte integrante da intervenção programada.

$\mathrm{Na}$ verdade, mais do que Educação de qualidade para todos, trata-se da provisão de serviços de qualidade a todas as pessoas, considerando que há segmento de pessoas com tamanho comprometimento que simplesmente seria, pelo menos por ora, completamente insano pensar em oferecer-lhes educação escolar. $O$ intenso debate que há hoje na Educação, motivado pela ideologia da inclusão, precisa ocorrer igualmente na Saúde e em outros setores importantes da sociedade.

\section{Mudanças na Pesquisa}

Por longo tempo, os serviços educacionais e de reabilitação no Brasil foram fundamentados em conhecimentos produzidos e sistematizados fora do país ou em experiências acumuladas junto a esses serviços, uma vez que nessa área praticamente não havia pesquisas realizadas com o propósito de produzir conhecimento a respeito dos 
http://dx.doi.org/10.5902/1984686X53133

aspectos educacionais e psicossociais das deficiências e do atendimento a pessoas com deficiência. Os relatos publicados em alguns periódicos eram predominantemente de experiências, algumas inovadoras e bem-sucedidas. Havia carência de pesquisas bem planejadas e conduzidas que contribuíssem para a construção do conhecimento que servisse de sólida base para os serviços destinados a pessoas com deficiência.

A formalização de cursos de pós-graduação stricto sensu, na década de 1960, foi um importante marco para a formação de novas gerações de pesquisadores. A pós-graduação nas áreas de Educação e Psicologia teve importante papel para o início sistemático de algumas pesquisas relacionadas a deficiências e atendimento a pessoas com deficiência. A criação do PMEE/UFSCar, em 1978, foi o maior marco para o desenvolvimento de pesquisas na área de Educação Especial, fato evidenciado pela emergência crescente de dissertações a partir do início da década de 1980, maioria defendida nesse Programa até a criação e consolidação de linhas de pesquisa em Educação Especial em outros Programas.

Os pesquisadores formados pelo PMEE e posteriormente pelo PPGEEs, atuando como docentes em várias universidades, públicas e privadas, disseminaram rapidamente a prática de pesquisa em Educação Especial. Ao lado disso, alguns Programas de PósGraduação em Educação, por meio de área de concentração ou linha de pesquisa em Educação Especial, contribuíram para delinear de vez uma área fértil e produtiva de pesquisa. E agora a recém-criada Pós-Graduação em Educação Especial, na Universidade Federal do Rio Grande do Norte, abre uma nova perspectiva com o seu Mestrado Profissional, talvez a preencher o vazio deixado pela extinção das Habilitações em Educação Especial.

Uma área de investigação se delineia paulatinamente, mediante a caracterização dos fenômenos a serem pesquisados, estabelecendo regiões fronteiriças com outras áreas de conhecimento de modo relativamente flexível para favorecer abordagens interdisciplinares nos estudos. A deficiência é um fenômeno multifacetado e multideterminado, o que requer a concorrência de diferentes disciplinas, que devem operar de modo solidariamente cooperativo. Uma breve olhadela nos trabalhos científicos publicados a respeito das deficiências permite identificar muitos referenciais teóricos presentes na literatura relativa a Educação Especial. A área tem se mostrado muito fértil para o uso, adequação e construção de diferentes concepções, revelando uma dinâmica acadêmica própria. 
http://dx.doi.org/10.5902/1984686X53133

A construção e consolidação de referenciais teóricos dependem de pesquisas bem conduzidas, com a abrangência e diversidade de problemas, e principalmente com delineamentos que garantam a confiabilidade dos dados em que se fundamentam tais referenciais. Isto nos coloca a questão do método de pesquisa, que considero um ponto delicado em Educação Especial. Quatro décadas atrás, as publicações da área de Educação Especial referiam-se basicamente a relatos de experiência, que foram bastante relevantes para a época, tendo permitido disseminar as práticas bem-sucedidas. Entretanto, para a formulação de referenciais teóricos sólidos, precisamos realizar pesquisas metodologicamente bem fundamentadas.

Pesquisas de alto nível dependem do amadurecimento acadêmico da área, propiciado pela ação coletiva por meio de diálogos e debates em publicações e encontros presenciais (hoje online também). A formação de novos pesquisadores, ensejada pelos programas de pós-graduação stricto sensu, e o consequente aumento no volume de pesquisas na área demandaram novos espaços de disseminação dos produtos assim gerados ${ }^{18}$. A criação do fórum de debates sobre as pesquisas teve significativa repercussão, não só no sentido da disseminação das pesquisas, como também no sentido de se construir uma perspectiva crítica de análise da produção do conhecimento na área.

Nessa breve caminhada, houve avanço no modo de buscar a construção do conhecimento em Educação Especial, com a crescente preocupação com o rigor metodológico. Muitas produções acadêmicas eram baseadas em reflexões, até em convicções pessoais. No decorrer das últimas quatro décadas, pesquisas empíricas começaram a ser realizadas em larga escala e amplamente debatidas em eventos e publicações da área. Essa prática permitiu incorporar de vez um princípio norteador da confiabilidade dos resultados de uma pesquisa, a intersubjetividade.

A preocupação pela confiabilidade dos dados coletados apareceu inicialmente em relação à observação do comportamento, numa típica situação em que o observador registra a ocorrência de diferentes comportamentos definidos previamente. $O$ coletor de dados deve observar o comportamento de um sujeito ou de um grupo de sujeitos e registrar a ocorrência de determinadas categorias de comportamentos. Ainda que cada categoria comportamental seja adequadamente definida e o observador convenientemente treinado, o procedimento envolve margem de erro, pois, em última instância, a decisão quanto à categoria a que corresponde um determinado comportamento vai depender do julgamento do observador. Adotou-se a prática de colocar aí um segundo observador (eventualmente 
http://dx.doi.org/10.5902/1984686X53133

até um terceiro), que faz a mesma tarefa do observador principal seguindo os mesmos critérios e procedimentos, porém de modo independente daquele. Coletados os dados, antes mesmo da sua análise, preliminarmente calcula-se a porcentagem de concordância, referida como fidedignidade interobservador, como um indicativo da confiabilidade dos dados coletados ${ }^{19}$.

As pesquisas em Educação Especial vêm utilizando muito frequentemente a coleta de dados por meio de entrevistas, as quais já de longa data são audiogravadas para posterior transcrição. Embora fosse concebível a conveniência de se assegurar a "fidedignidade interentrevistadores 20 ", não há tal prática, considerando que não é aceitável um participante ser entrevistado duas ou três vezes por entrevistadores diferentes. Especial cuidado ocorre então em relação à elaboração de um bom roteiro que pode minimizar a possibilidade de ocorrência de vieses na coleta de dados.

Um procedimento amplamente empregado para a análise da transcrição da entrevista é baseado na identificação de categorias temáticas no discurso de cada entrevistado. É neste momento que a interpretação de quem está fazendo a identificação de categorias temáticas previamente definidas pode interferir no resultado. Daí, para assegurar a fidedignidade dos dados com os quais será feita toda a análise, comumente se faz uso de uma segunda pessoa e eventualmente uma terceira, referidas como juízes, a fazerem a categorização. A porcentagem de concordância na categorização, identificada como concordância interjuízes, indica o grau de intersubjetividade no julgamento.

Adicionalmente, poderia ser utilizada rotineiramente uma análise preliminar da interação verbal havida durante a entrevista, com o intuito de verificar a completude e adequação das respostas do entrevistado e o cuidado e atenção com que o entrevistador conduziu a coleta de dados (OLIVEIRA, 2002). Essa análise, em conjunto com a concordância interjuízes na categorização temática do discurso de cada participante, pode contribuir para aumentar a confiabilidade dos dados assim coletados e analisados.

Esses cuidados revelam maturidade acadêmica que vem ocorrendo na área de Educação Especial. Há, entretanto, algumas fragilidades a serem superadas, talvez nas próximas quatro décadas. Quero destacar três delas: a pouca representatividade das amostras utilizadas, a não equivalência entre os grupos submetidos a diferentes procedimentos e a limitação dos delineamentos de pesquisa empregados.

$\mathrm{Na}$ maioria das pesquisas em Educação Especial, são utilizados grupos de participantes, com o intuito de buscar generalidade dos achados. Convenientemente 
http://dx.doi.org/10.5902/1984686X53133

referidos como amostras por conveniência, quase sempre são utilizados, por razões práticas e/ou éticas, os grupos naturalmente constituídos, o que coloca a questão da representatividade das amostras em relação à população a que se referem, limitando assim a generalização dos resultados.

Nos delineamentos quase-experimentais em que se utilizam dois (ou mais) grupos para a composição do grupo experimental e o de controle, habitualmente são utilizados grupos já constituídos naturalmente. Sem a garantia da equivalência entre os grupos, qualquer conclusão sobre possíveis efeitos da intervenção fica prejudicada. Uma alternativa é a avaliação antes da intervenção para comparar os grupos e encontrar alguma evidência da equivalência entre eles. É um procedimento adequado, diante da impossibilidade de se constituírem dois grupos estatisticamente equivalentes, porém novos problemas podem ser introduzidos: os efeitos da intervenção, evidenciados na comparação do pós-teste dos dois grupos, podem ser resultados da interação entre a avaliação prévia e a intervenção; podem também ser resultados da interação entre a intervenção e algum evento estranho ao delineamento ocorrido nesse período que isoladamente não afetou o grupo de controle.

A outra fragilidade diz respeito ao delineamento de pesquisa. $O$ estudo já referido de Glat, Omote e Pletsch (2014) identificou diferentes tipos de pesquisa relatados nas três edições de quatro grandes eventos científicos de Educação Especial no Brasil. Nesse levantamento, $51 \%$ dos trabalhos apresentados se referiam a estudos descritivos, 17\% a ensaios teóricos, $16 \%$ a relatos de experiência, $12 \%$ a delineamento pré-experimental e $2 \%$ a delineamentos quase-experimental e experimental. A observação informal nas publicações e trabalhos apresentados em eventos científicos sugere não ter havido mudança nesse quadro nos últimos 5 ou 6 anos.

Os estudos descritivos, realizados com o devido rigor metodológico, da sua concepção até a análise de dados, é o primeiro importante passo para a construção de conhecimento em Educação Especial. A partir dessa descrição, podem ser inferidas possíveis relações funcionais entre eventos observados ou entre diferentes propriedades de um evento, mais comumente a relação de dependência linear ou correlação. Para a construção de conhecimento a respeito do fenômeno, é necessário ir além da descrição global do objeto de estudo, observando detalhes específicos mediante a mensuração deles com o uso de instrumentos construídos para esse fim. Os resultados dessa mensuração, devidamente analisados por meio de recursos estatísticos, completam a descrição do fenômeno ${ }^{21}$. 
http://dx.doi.org/10.5902/1984686X53133

Em qualquer área de conhecimento, o interesse dos pesquisadores não se limita a descrever detalhadamente e com rigor os fenômenos envolvidos. Compreendê-los é uma necessidade instrumental e não a de satisfação da curiosidade. A intervenção na situação, com o propósito de produzir resultados específicos, requer mais do que a descrição do fenômeno tal como ele ocorre. É preciso identificar as relações de causalidade entre os eventos.

As pesquisas ex post facto permitem identificar as correlações; para a identificação de relações causais, são necessários delineamentos experimentais. O estudo de Glat, Omote e Pletsch (2014) evidenciou que 14\% das pesquisas relatadas em três edições de quatro grandes eventos científicos no país, no período de 2008 a 2013, haviam utilizado delineamentos experimentais ${ }^{22}$.

Os delineamentos experimentais podem ser planejados de diferentes maneiras para atender o propósito do pesquisador e em função das peculiaridades do fenômeno estudado, sempre com o intuito de gerar dados que indiquem a relação de causalidade com a maior confiabilidade possível. Entretanto, sempre existe a possibilidade de o resultado ser afetado por alguma variável não controlada pelo pesquisador, até porque é impossível conhecer todas as variáveis estranhas ao delineamento, que podem interferir nos resultados obtidos. Além disso, o próprio fenômeno sob estudo está em constante transformação, e muito rápida no caso de Educação Especial.

Do ponto de vista epistemológico, as conclusões a que nos levam mesmo as pesquisas mais bem concebidas e executadas são provisórias pelas razões apontadas no parágrafo anterior. Assim, os estudos de replicação, embora nem sempre devidamente valorizados, adquirem particular importância. As pesquisas de replicação podem contribuir para melhorar a generalização dos achados, uma vez que, no conjunto, significam variadas amostras de uma população, ainda que cada uma delas não tenha garantia da representatividade. Podem ser planejadas com o intuito de controlar variáveis estranhas específicas não consideradas nos estudos anteriores. Elas significam uma promissora alternativa para aumentar a confiabilidade e efetividade dos referenciais teóricos em construção, em permanente construção.

A área de Educação Especial precisa ousar mais no uso de delineamentos experimentais para estabelecer relações causais entre os eventos envolvidos, para que seja possível planejar intervenções junto a pessoas com deficiência, seus familiares, as instituições escolares, a comunidade em geral, etc. com o pleno conhecimento das 
http://dx.doi.org/10.5902/1984686X53133

condições que precisam ser rigorosamente controladas para produzir o resultado pretendido. Chegará o momento em que se justificarão até as pesquisas experimentais de laboratório, que hoje podem parecer tão estranhas em Educação Especial. Esses avanços no refinamento dos estudos não se confundem absolutamente com o reducionismo tão temido. A compreensão plena de um fenômeno requer a sua visão global constituída por importantes detalhes - como as correlações e relações causais entre diferentes variáveis que o compõem. Enquanto não ousarmos nessa direção, estaremos procurando atingir o alvo por meio de bacamarte.

\section{Referências}

ALMEIDA, Carmelita Saraiva. Análise dos Motivos de Encaminhamento de Alunos de Classes Comuns a Classes Especiais de Escolas Públicas de Primeiro Grau. 1984. Dissertação (Mestrado em Educação Especial) - Universidade Federal de São Carlos, São Carlos.

CAMPBELL, Donald T.; STANLEY, Julian C.Delineamentos Experimentais e QuaseExperimentais de Pesquisa. São Paulo: EPU e EDUSP, 1979.

DENARI, Fátima Elizabeth.Análise de Critérios e Procedimentos para a Composição de Clientela de Classes Especiais para Deficientes Mentais Educáveis. 1984. Dissertação (Mestrado em Educação Especial) - Universidade Federal de são Carlos, São Carlos.

\section{ENUMO, Sônia Regina Fiorim. A Formação Universitária em Educação Especial -} Deficiência Mental no Estado de São Paulo: suas características administrativas, curriculares e teóricas. 1985. Dissertação (Mestrado em Educação Especial) - Universidade Federal de São Carlos, São Carlos.

GLAT, Rosana; OMOTE, Sadao; PLETSCH, Márcia Denise. Análise crítica da produção do conhecimento em Educação Especial. In: S. OMOTE; A.A.S. OLIVEIRA; CHACON, M.C.M. (Orgs.). Ciência em Conhecimento em Educação Especial.São Carlos: Marquezini\& Manzini e ABPEE, 2014, p. 25-44.

GROSSMAN, Herbert J. Manual on Terminology and Classification in Mental Retardation. Washington: American Association on Mental Deficiency, 1973. (retirado apud)

HEBER, Rick A. Modifications in the Manual on Terminology and Classification in Mental Retardation. American Journal of Mental Deficiency, v. 65, p. 499-500, 1961.

Retirada a referência de Jervis (1961).

OLIVEIRA, Anna Augusta Sampaio.Representações Sociais sobre Educação Especial e Deficiência: o ponto de vista de alunos e professores. 2002. Tese (Doutorado em Educação) - Faculdade de Filosofia e Ciências, Universidade Estadual Paulista, Marília. 
http://dx.doi.org/10.5902/1984686X53133

OMOTE, Sadao. Aspectos socio-familiares da deficiência mental. Revista Marco, v. 1, n. 1, p. 99-113, 1979.

OMOTE, Sadao. A integração do deficiente: um pseudo-problema científico. Temas em Psicologia, n. 2, p. 55-62, 1995.

OMOTE, Sadao. Normalização, integração, inclusão... Ponto de Vista, v. 1, n. 1, p. 4-13, 1999.

OMOTE, Sadao. Classes especiais: comentários à margem do texto de Torezan e Caiado. Revista Brasileira de Educação Especial, v. 6, n. 1, p. 43-64, 2000.

OMOTE, Sadao. Algumas tendências (ou modismos?) recentes em Educação Especial e a Revista Brasileira de Educação Especial. Revista Brasileira de Educação Especial, v. 9, n. 1, p. 25-38, 2003.

OMOTE, Sadao. Inclusão escolar e social: a ética entre o estigma e a inclusão. In: L.A.R. MARTINS; G.N.L. PIRES; J. PIRES (Orgs.) Inclusão Escolar e Social: novos contextos, novos aportes. Natal: Editora da UFRN, 2012. p. 39-54.

PASCHOALICK, Wanda Ciccone. Análise do Processo de Encaminhamento de Crianças às Classes Especiais para Deficientes Mentais Desenvolvido nas Escolas de 10 Grau da Delegacia de Ensino de Marília. 1981. Dissertação (Mestrado em Educação) - Pontifícia Universidade Católica, São Paulo.

PIROVANO, Kátia Regina Coutinho. Caminho Suado - a Trajetória Escolar de Alunos Encaminhados para Classes Especiais de Educação Especial para Deficientes Mentais em Escolas Públicas da Rede Estadual de São Paulo. 1996. Dissertação (Mestrado em Educação) - Faculdade de Filosofia e Ciências - Universidade Estadual Paulista, Marília.

RODRIGUES, Olga Maria Piazentim Rolim. Caracterização das Condições de Implantação e Funcionamento de Classes Especiais e Caracterização das

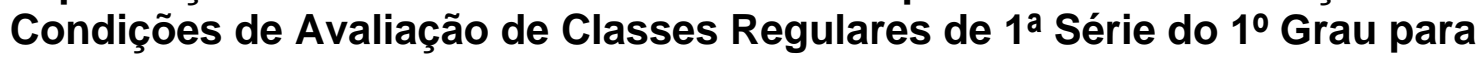
Fundamentar uma Proposta de Intervenção. 1982. Dissertação (Mestrado em Educação Especial) - Universidade Federal de São Carlos, São Carlos.

SCHNEIDER, Doriti. "Alunos Excepcionais": um estudo de caso de desvio. In: G. VELHO (Org.) Desvio e Divergência. Rio de Janeiro: Zahar, 1974, p. 52-81.

TELFORD, Charles W.; SAWREY, James M. O Indivíduo Excepcional. Rio de Janeiro: Zahar, 1976.

UNESP-Universidade Estadual Paulista. Comissão de Educação Especial/Relatório. São Paulo, 1977. 
http://dx.doi.org/10.5902/1984686X53133

\section{Notas}

${ }^{1}$ Fiz opção por escrever na primeira pessoa do singular, declarando que se trata da expressão de um ponto de vista particular, que imagino possa ser de algum interesse acadêmico. Últimos 40 anos significam um período curto, mas efervescente, e talvez não seja tarefa fácil encontrar documentos suficientes que permitam uma reconstituição histórica detalhada desse breve período. Talvez a memória viva possa conter ingredientes implicativos que a memória documental não revela. Os marcos históricos apontados, como também a interpretação das suas implicações, certamente contêm o viés pessoal de quem viveu na primeira pessoa este período de tantas transformações. Contrariando um pouco o meu hábito, farei uso de muitas notas de rodapé para complementar algumas informações sem desviar o texto do seu fluxo e para explicitar o meu posicionamento pessoal, sempre que julgar necessário ou conveniente. Peço desculpas pela eventual falha na memória, especialmente com relação a datas.

${ }^{2}$ Em respeito à minha dificuldade de aderir ao modismo representado pelos tantos nomes efêmeros com referência a deficiências, mantenho a terminologia corrente na época a que se refere o texto.

${ }^{3}$ Há uma enormidade de documentos legais brasileiros recentes, que normatizam o atendimento educacional a crianças e jovens com deficiência, transtorno global do desenvolvimento e altas habilidades/superdotação, referidos como público-alvo da Educação Especial. Conforme já explicitei, não é meu propósito fazer uma análise histórica por meio desses documentos. Foi feita uma brevíssima referência a alguns marcos históricos que considero particularmente importantes, apenas para dar uma ideia, ainda que muito sucintamente, de um background que pode emprestar uma significação específica a alguns fatos a serem considerados no texto.

${ }^{4}$ Embora reconheça importantes fatos ocorridos em alguns outros Estados, que se destacaram na Educação Especial, deter-me-ei nestes dois acontecimentos, porque deles participei pessoal e ativamente, razão pela qual o escopo do texto foi restrito ao Estado de São Paulo, contrariando a sugestão dos organizadores do dossiê.

${ }^{5}$ Havia boas razões para essa opção, que vão muito além da frequência maior de ocorrência de deficiência mental, comparativamente a outras deficiências. Não serão discutidas aqui por fugirem ao escopo do texto,mas facilmente se podem identificar motivações sociais de diferentes ordens subjacentes a essa escolha.

${ }^{6}$ Havia, na época, um número insignificante de livros da área de Educação Especial traduzidos para a língua portuguesa e menos ainda de autoria brasileira. Havia também um número muito pequeno de dissertações ou teses tratando de questões relacionadas às deficiências, as quais eram de acesso difícil aos eventuais leitores.

${ }^{7} \mathrm{Na}$ oportunidade, havia Faculdades estaduais em várias cidades no interior do Estado, conhecidas como Institutos Isolados.

${ }^{8}$ Um dos princípios norteadores era a não repetição do mesmo curso, com poucas exceções, em diferentes campi, o que levou à extinção de alguns cursos.

${ }^{9}$ Esta era a denominação considerada mais adequada para a deficiência auditiva.

10 Um docente, contratado em 1977, matriculou-se no PMEE/UFSCar já na primeira turma de 1978. Quando da implantação da HEE/UNESP na área de deficiência física, em 1986, seis docentes foram contratados, entre os quais três já estavam cursando o PMEE/UFSCar e dois outros iniciaram incontinenti a sua formação acadêmica no mesmo Programa. No decorrer dos anos seguintes, vários docentes da HEE/UNESP fizeram formação no PMEE/UFSCar (posteriormente PPGEEs/UFSCar).

${ }^{11}$ Creio que hoje podemos caracterizar a Educação Especial também como área de conhecimento e não apenas área de aplicação, como era concebida inicialmente.

${ }^{12}$ A AAMD teve anteriormente outras duas designações, nos tempos em que se usava o termo feebleminded. $\mathrm{Na}$ penúltima atualização, passou a chamar-se American Association on Mental Retardation e, mais recentemente, American Association on intellectual and Developmental Disabilities, designação que continua até hoje.

${ }^{13}$ Quando a área de deficiência física foi implantada em 1986, a disciplina Alterações Sensoriais e Motoras de Crianças Deficientes já havia sido extinta, mas a de Divergências Sociais foi ministrada até a última turma. 
http://dx.doi.org/10.5902/1984686X53133

${ }^{14}$ Numa futura avaliação e revisão dessas práticas escolares, talvez haja a necessidade de se reconsiderarem seriamente algumas das especificidades em termos das necessidades educacionais especiais, delineando claramente as competências nas quais o tratamento precisa ser diferenciado para cada caso.

${ }^{15}$ Eis um nome antigo que se referia à ampla categoria de pessoas, incluindo tanto as que estavam abaixo quanto acima da normalidade estatística em alguma característica considerada relevante. Mas, esse nome era de serventia discutível. Em vez disso, eram utilizados nomes específicos para cada condição, inclusive com a definição de subcategorias e respectivos nomes.

${ }^{16}$ Os tradicionais nomes como débil mental, idiota, imbecil, mentecapto, mongolóide e oligofrênico foram substituídos por retardado mental (limítrofe, educável, treinável, semidependente e dependente ou limítrofe, benigno, moderado, severo e profundo), deficiente mental, deficiente intelectual, portador da síndrome de Down. Muitos outros nomes específicos foram utilizados com referência a outras condições de excepcionalidade - cego, amblíope, baixa visão, deficiente visual, surdo-mudo, surdo, hipoacúsico, deficiente auditivo, deficiente da audiocomunicação, aleijado, inválido, deficiente físico, deficiente ortopédico, paraplégico, tetraplégico, paralítico cerebral (espástico, atetóide e atáxico), gago, tartamudo, epiléptico, gênio, superdotado, talentoso, criativo, etc. A lista pode se estender bastante com outros nomes que, em diferentes momentos, serviam para designar categorias ou subcategorias específicas de excepcionalidade.

${ }^{17}$ Referem-se a Jornada de Educação Especial (UNESP), Congresso Brasileiro Multidisciplinar de Educação Especial (UEL), Congresso Brasileiro de Educação Especial (UFSCar) e Seminário Nacional sobre Educação e Inclusão Socialde Pessoas com Necessidades Educacionais Especiais (UFRN).

${ }^{18}$ Assim é que, em 1984, o PMEE iniciou o Ciclo de Estudos sobre Deficiência Mental, com o objetivo precípuo de divulgar as pesquisas relatadas em dissertações de seus discentes. Foi uma decisão feliz que permitiu grande visibilidade a um centro emergente de pesquisas em Educação Especial. O evento, realizado anualmente, logo se revelou um importante espaço para a reunião de pesquisadores da área de Educação Especial, provenientes de todas as regiões do país, o que acabou por dar origem ao Congresso Brasileiro de Educação Especial. Vários outros eventos científicos foram criados, alguns já extintos e outros ainda vigentes. Em 1987, a Universidade Federal de Santa Maria iniciou a publicação dos seus Cadernos de Educação Especial, cujo título foi alterado para Revista de Educação Especial em 2004. Em 1992, foi a vez da Revista Brasileira de Educação Especial, tendo sido criada a Associação Brasileira de Pesquisadores em Educação Especial, no ano seguinte, para dar suporte à manutenção do periódico. Esses dois periódicos, academicamente os mais representativos da área, vêm contribuindo para a disseminação de pesquisas e pensamentos da área de Educação Especial no Brasil.

${ }^{19}$ Esse procedimento - definição das categorias comportamentais, treinamento de observadores e o registro de ocorrência de comportamentos - é amplamente facilitado hoje pelos recursos de gravação de imagem.

${ }^{20}$ A relação entrevistador-entrevistado pode ser mais interativa que a relação observador-observado, razão pela qual eventual influência do coletor de dados pode ser maior nas falas audiogravadas do que nas imagens gravadas em situação de observação do comportamento.

${ }^{21}$ Os relatos orais obtidos de entrevista ou descrições comportamentais obtidas de observação podem sugerir uma possível relação funcional entre dois ou mais aspectos do fenômeno observado. Se esse detalhe é relevante, dados quantitativos precisam ser obtidos para, por meio da competente análise estatística, identificar e descrever com mais precisão essas relações funcionais. A relação entre duas variáveis pode ser de dependência linear (correlação), na qual ambas as variáveis crescem ou decrescem na mesma direção (correlação direta) ou em direções opostas (correlação inversa). Mais ainda, essa análise estatística fornece um indicador da confiabilidade, por meio da probabilidade de a conclusão ser equivocada. Identifico uma certa confusão envolvendo a questão da qualidade e quantidade, mas não há espaço aqui para tratar desse problema.

${ }^{22}$ Embora haja importantes diferenças em termos da confiabilidade dos resultados, não serão tratados separadamente os três delineamentos experimentais na presente discussão. Para o leitor interessado nas características de cada delineamento, há um pequeno grande clássico de Campbell e Stanley (1979). 


\section{Correspondência}

Sadao Omote -Universidade Estadual Paulista Júlio de Mesquita Filho, Faculdade de Filosofia e Ciências - Campus de Marília, Av. Higyno Muzzi Filho, 737, Campus Universitário, Marília, São Paulo- Brasil.

CEP: $17525-900$

\section{(c) (i) (9)} 4.0 International (CC BY-NC 4.0) 